\title{
KONTRIBUSI LINGUISTIK PEDAGOGIS DALAM PEMBENAHAN MUTU PEMBELAJARAN BAHASA ARAB
}

\author{
Dinni Masyitoh Lindrianawati \\ UIN Sunan Kalijaga_ \\ Corresponding Author: dhinimasytoh@gmail.com
}

\section{Article History}

Submitted: 22 Sept 2020; Revised: 12 Dec 2020; Accepted:19 Dec 2020

DOI $10.20414 /$ tsaqafah.v19i2.2552

\begin{abstract}
This paper aims to provide insight to all learners, researchers, and practitioners in the field of Arabic, especially Arabic language teachers, as a final project of pedagogical linguistics. The number of Arabic learning problems that occur in the field is due to several reasons, it can affect the quality of learning Arabic in schools. Therefore, pedagogical linguistics contributes to providing several notes as a solution to improving the quality of learning Arabic in schools, one of which is fixing the syllabus of learning operations. The method used in this paper is literature study, namely by collecting various literatures on pedagogical linguistics and literature on the quality of Arabic learning, which the authors then synthesize so that it becomes one of the solutions for improving the quality of Arabic learning in schools to make it even better.
\end{abstract}

Keywords: pedagogical linguistics, quality of learning, arabic

Abstrak: Tulisan inibertujuan untukmemberikan wawasan kepada seluruh pembelajar, peneliti, maupun praktisi di bidang bahasa Arab khususnya guru bahasa Arab, sebagai tugas akhir dari linguistik pedagogis. Banyaknya problem pembelajaran bahasa Arab yang terjadi di lapangan dikarenakan oleh beberapa sebab, dapat mempengaruhi mutu pembelajaran bahasa Arab di sekolah sekolah. Maka dari itu linguistik pedagogis berkontribusi memberikan beberapa catatan sebagai salah satu solusi pembenahan mutu pembelajaran bahasa Arab di sekolah, salah satunya adalah membenahi silabus operasi pembelajaran. Metode yang digunakan dalam tulisan ini yaitu studi pustaka, yaitu dengan mengumpulkan berbagai literatur tentang linguistik pedagogis dan literatur tentang mutu pembelajaran bahasa Arab, yang kemudian disintesiskan penulis sehingga menjadi salah satu solusi pembenahan mutu pembelajaran bahasa Arab di sekolah agar menjadi lebih baik lagi.

Kata kunci: Linguistik Pedagogis, Mutu Pembelajaran, Bahasa Arab 


\section{A. Pendahuluan}

Dalam perkembangan pembelajaran bahasa Arab di Indonesia seringkali guru atau siswa - sebagai komponen utama dalam pembelajaran - mengalami berbagai kesulitan dan permasalahan pembelajaran, baik persoalan yang bersumber dari siswa maupun masalah-masalah yang dihadapi oleh guru, sehingga dapat menghambat pada ketercapaian tujuan pembelajaran dengan baik. Hal ini dapat dimaklumi, mengingat banyaknya perbedaan-perbedaan sistem antara bahasa Arab sebagai bahasa kedua yang dipelajari dan sistem bahasa Indonesia yang sudah melekat erat pada diri siswa di Indonesia. Perbedaan-perbedaan itu dapat dilihat misalnya pada aspek fonem, gramatikal atau kaedah bahasa, sistem kosa kata, dan gaya bahasa $(u s l u b)^{1}$.

Sejatinya proses pembelajaran bahasa Arab melibatkan banyak hal seperti kurikulum, guru, perencanaan pembelajaran, pembelajar, mata pelajaran, media pembelajaran dan evaluasi. Guru memegang peranan penting dalam hal ini. Dimana guru merupakan juru kunci yang berperan penting mensukseskan proses pembelajaran. Siswa sebagai pemeran utama pembelajaran adalah subjek belajar yang menuntut guru untuk mengembangkan pengetahuannya. Alih-alih menguasai bahasa Arab, kebanyakan siswa kurang apresiatif terhadap pembelajaran bahasa Arab, personalia guru bahasa Arab, metode pengajaran yang diterapkan, tingkat kebosanan dalam proses pembelajaran yang masih tinggi. Hal ini semakin menegukan potret rendahnya mutu pembelajaran bahasa Arab di Indonesia.

Gurulah yang paling bertanggungjawab atas rendahnya mutu pembelajaran bahasa Arab. Sebab melalui gurulah proses meraih tujuan pembelajaran yang telah ditetapkan ${ }^{2}$ diwujudkan dalam aktifitas-aktifitas nyata. Melalui guru pula rancangan kurikulum diterjemahkan dalam berbagai aktifitas pembelajaran. Singkatnya, hanya gurulah satu-satunya subjek yang berinteraksi sekaligus mengorkestrasi proses pembelajaran secara langsung dengan pembelajar di dalam kelas.

Nababan (1993) mengatakan ada empat faktor yang mempengaruhi kesuksesan pembelajaran bahasa Arab, diantaranya adalah guru yang kompeten dan inspiratif ${ }^{3}$. Nababan (1993) juga mengatakan bahwa proses belajar bahasa asing itu sulit, maka dalam belajar bahasa asing ini diperlukan keterlibatan guru yang kompeten dan isnpiratif.

Setiap proses pembelajaran dilaksanakan guna mencapai tujuan yang telah ditetapkan ${ }^{4}$. Oleh sebab itu, semakin tinggi peluang tercapainya tujuan dalam pembelajaran tercipta, semakin tinggi pula mutu pembelajaran tersebut. Berpangkal pada pemahaman mutu pembelajaran di atas, pembelajaran yang bermutu bermuara pada sebuah proses yang terfokus pada pembelajar, dibingkai dengan aktifitas yang

1 Mochamad Ismail, "Peran Psikolinguistik Dalam Pembelajaran Bahasa Arab” Vol 8 No 2 (2013): 2, https: / / ejournal.unida.gontor.ac.id/index.php/tadib/article/view/ 508.

2 Muhajir, Arah Baru Pengajaran Bahasa Arab (Yogyakarta: FITK UIN SUKA, 2017), 5.

3 Nababan, Metodologi Pengajaran Bahasa (Jakarta: Gramedia Pustaka Utama, 1993),21.

4 Wina Sanjaya, Perencanaan dan Desain Pembelajaran, (Jakarta: Kencana, 2013), hlm.10. 
menyenangkan, bergembira, dan demokratis dalam menghargai setiap pendapat, sehingga pada akhirnya substansi setiap pembelajaran benar-benar dihayati ${ }^{5}$.

Secara lebih luas Edi Suhadi ( $\mathrm{dkk}$ ) menjelaskan mutu pembelajaran sebagai keberhasilan sekolah dalam mencapai tujuan pembelajaran. Dalam pelaksanannya, mutu pembelajaran merupakan perpaduan antara proses dan hasil belajar yang dicapai pembelajar dengan dukungan pendidik dan tenaga kependidikan. Pembelajaran bermutu bila semua unsur berpadu menunjukkan kinerja terbaiknya dalam melaksanakan tugas dan tanggungjawabnya. ${ }^{6}$

Linguistik pedagogis mempunyai peran yang sangat penting dalam sebuah pembelajaran bahasa. Mengingat bahwa linguistik pedagogis merupakan cabang dari linguistik terapan yang khusus menganalisis, menerangkan, dan menjelaskan tentang praktik pelaksanaan pengajaran bahasa dan pendidikan bahasa yang berlandaskan teori-teori kebahasaan ${ }^{7}$

Dalam hal ini penulis akan mengupas beberapa kontribusi linguistik pedagogis dalam pembenahan mutu pembelajaran bahasa Arab dengan beberapa catatan yang penulis sintesiskan dapat memberikan solusi pada pembenahan mutu pembelajaran bahasa Arab.

\section{B. Landasan Teori}

Untuk memahami sebuah tulisan diperlukan adanya teori untuk memperkuat suatu asumsi tertentu, Begitu pula tulisan ini yang juga membutuhkan landasan teori. Berikut pemaparannya:

\section{Linguistik pedagogis}

Hornberger dan Spolsky di Spolsky dan Hult (2008: 2) mendefinisikan linguistik pendidikan atau linguistik pedagogis sebagai bidang studi yang mengintegrasikan penelitian dalam bidang linguistik dan disiplin ilmu yang lain terkait ilmu sosial untuk menyelidiki berbagai isu-isu yang berkaitan dengan bahasa dan pendidikan secara holistik. Homberger dan spolsky juga (Hornberger, 2001; Spolsky, 1978) menyatakan bahwa "Educational linguistics is an area of study that integrates the research tools of linguistics and other related disciplines of the social sciences in order to investigate holistically the broad range of issues related to language and education", yang mengandung arti bahwa linguistik pedagogis atau linguistic edukasional adalah bidang studi yang mengintegrasikan alat penelitian linguistik dan disiplin lainnya yang berkaitan dengan ilmu-ilmu sosial dalam rangka menyelidiki secara menyeluruh pada berbagai masalah yang berkaitan dengan bahasa dan pendidikan ${ }^{8}$

5 Imam Makruf,"Standarisasi Mutu Pembelajaran: Studi di IAIN Surakarta dan Kasem Bundit University Thailand", hlm. 103.

6 Edi Suhadi (dkk),"Pengebangan Motivasi dan Kompetensi Guru dalam Peningkatan Mutu Pembelajaran Madrasah", Jurnal Ta'dibuna, Vol. 3, No. 1, April 2014, hlm. 48.

7 Daniel Parera, Linguistik Edukasional (Jakarta: Erlangga, 1987), 1.

8 Bernard Spolsky, Educational Linguistics: An Introduction terj. Rowley (London: Newbury House, 
Sedangkan Richards dan Schmidt (2002: 330) di dalam kamus pengajaran bahasa dan linguistik terapan mendefinisikan linguistik pendidikan sebagai istilah yang kadang-kadang digunakan untuk merujuk kepada cabang Linguistik terapan yang berkaitan dengan hubungan antara bahasa dan pendidikan'.

Unsworth (2015: 3) menyatakan bahwa linguistik pendidikan berkaitan dengan studi bahasa dalam mengajar dan belajar. Dengan demikian, ia memiliki kepentingan di dalam sistem linguistik dan perannya dalam belajar, juga seperti apa jenis pengetahuan tentang bahasa yang harus diajarkan kepada siswa ${ }^{10}$.

Sedangkan menurut Parera (1987) Linguistik edukasional atau linguistik pedagogis merupakan salah satu cabang ilmu linguistik terapan yang khusus menganalisis, menerangkan, dan menjelaskan tentang praktikpelaksanaan pengajaran bahasa dan pendidikan bahasa yang berlandaskan teori-teori kebahasaan ${ }^{11}$

Berbeda dengan Parera, Spolsky (1974: 3) menyatakan bahwa linguistik pendidikan adalah disiplin ilmu yang tugas utamanya adalah untuk menawarkan informasi yang relevan untuk merumuskan kebijakan pendidikan bahasa dan pelaksanaannya ${ }^{12}$.

Hornberger di Benson (2005: 8) menyatakan bahwa linguistik pendidikan mengkhususkan dirinya sendiri terhadap isu-isu di keanekaragaman linguistik dan budaya dengan pendekatan untuk belajar dan mengajar yang merangkul kepentingan lokal, nasional dan internasional. Kemudian, ia juga mengatakan bahwa linguistik pendidikan termasuk pemerolehan bahasa kedua, pemilihan bahasa, pemeliharaan dan pergeseran bahasa, bahasa dan etnis, analisis deskriptif, pidato dan wacana, pendidikan, implikasi keanekaragaman linguistik, pendidikan perencanaan bahasa, dwibahasa, interaksi pengucapan dan buta huruf ${ }^{13}$.

Dari teori teori tersebut, penulis sistesiskan bahwasanya linguistik pedagogis adalah cabang ilmu linguistik terapan yang khusus menganalisis, menerangkan, dan menjelaskan tentang praktik pelaksanaan pengajaran bahasa dan pendidikan bahasa yang berlandaskan teori-teori kebahasaan yang tugas utamanya adalah untuk menawarkan informasi yang relevan untuk merumuskan kebijakan pendidikan bahasa dan pelaksanaannya.

1978), 65.

9 Richards, Jack C. and Richard Schmidt. 2002. Dictionary of Language Teaching and Applied Linguistics. London: Longman, 89

10 Christie, Frances., Unsworth, Len. 2015. Developing dimensions of an educational linguistics. web.uam.es/departamentos/filoyletras/.../LFC.../ChristieUnsworth05.doc (Accessed on 20 August 2015).

11 Parera, 1.

12 Spolsky, B. and Hult, F.M. 2008. The Handbook of Educational Linguistics. Victoria: Blackwell Publishing, 156.

13 Benson, Carol. 2005. The importance of mother tongue-based schooling for educational quality. Stockholm: Stockholm University Press, 174. 


\section{Mutu pembelajaran}

Menurut KBBI (Kamus Besar Bahasa Indonesia), mutu adalah (ukuran) baik buruk suatu benda; kadar; taraf atau derajat (kepandaian, kecerdasan, dan sebagainya); kualitas ${ }^{14}$.

Dalam pandangan Zamroni dikatakan bahwa peningkatan mutu sekolah adalah suatu proses yang sistematis yang terus menerus meningkatkan kualitas proses belajar mengajar dan faktor-faktor yang berkaitan dengan itu, dengan tujuan agar menjadi target sekolah dapat dicapai dengan lebih efektif dan efisien ${ }^{15}$.

Menurut Garvin dan Davis dalam buku abdul hadis dan Nurhayati, penulis buku yang berjudul manajemen mutu pendidikan berpendapat bahwa Mutu adalah suatu kondisi dinamik yang berhubungan dengan produk, tenaga kerja, proses dan tugas serta lingkungan yang memenuhi atau melebihi kebutuhan pelanggan ${ }^{16}$.

Dari beberapa pengertian diatas, dapat disimpulkan bahwa peningkatan mutu pembelajaran yaitu suatu rangkaian proses kegiatan pembelajaran yang harus dikerjakan oleh pendidik dan peserta didik untuk memperbaiki kualitas atau mutu dari pembelajaran tersebut secara terus menerus dengan tujuan pembelajaran dapat berjalan secara efektif dan efisien, guna memberi nilai tambah pada hasil lulusan dari suatu lembaga pendidikan. Dan proses pembelajaran tersebut terdiri atas seluruh komponen materi pembelajaran dan prosedur kegiatan belajar mengajar yang dilakukan oleh guru yang akan disampaikan kepada peserta didik untuk mencapai tujuan pembelajaran yang ingin dicapai.

Pembelajaran yang bermutu dihasilkan oleh guru yang bermutu pula. Kecakapan guru dalam mengelola proses pembelajaran menjadi inti persoalannya. Begitu pula jika seorang guru bahasa Arab mempunyai mutu yang bagus, maka akan menghasilkan pembelajaran bahasa Arab yang bagus pula. Tahapan-tahapan dalam proses pembelajaran sedikitnya harus meliputi fase-fase berikut (Surakhmad 1986:45$46)^{17}$ :

1. Menetapkan tujuan pembelajaran yang kan dicapai

2. Memilih dan melaksanakan metode yang tepat dan sesuai materi pelajaran serta memperhitungkan kewajaran metode tersebut dengan metode-metode yang lain

3. Memilih dan mempergunakan alat bantu atau media guna membantu tercapainya tujuan

4. Melakukan penilaian atau evaluasi pembelajaran

\footnotetext{
14 https://kbbi.kemdikbud.go.id/entri/Mutu

15 Zamroni, Meningkatkan Mutu Sekolah, (Jakarta : PSAP Muhamadiyah, 2007), hal 2

16 Abdul Hadis \& Nurhayati, Manajemen Mutu Pendidikan, (Bandung : Alfabeta 2010), Cet 1, hal. 86

17 Surakhmad, W. 1986. Metodologi Pengajaran Nasional. Bandung: Jemmars
} 
Dengan demikian mutu pembelajaran adalah seperangkat asumsi filosofis mengenai proses pembelajaran yang dapat mengantarkan pembelajar pada pencapaian tujuan belajar yang telah ditetapkan secara maksimal, bahwa pembelajaran yang bermutu tidak hanya berupa transfer pengetahuan (aspek intelektual), lebih dari itu pembelajaran yang bermutu adalah pembelajaran yang juga berhasil mengantarkan pembelajar yang terampil (aspek psikomotor) disertai moral (aspek afeksi) yang baik. Mutu pembelajaran juga merupakan sebuah metodologi yang berisi seperangkat rancangan perubahan, rancangan agenda dan rancangan problem solving dari sebuah sistem pembelajaran yang terpadu antara pembelajar, pendidik dan tenaga kependidikan untuk mencapai tujuan pembelajaran yang telah ditetapkan. Dengan demikian mutu pembelajaran adalah cerminan dari sekolah/madrasah yang berhasil dalam melaksanakan proses belajar-mengajar.

\section{Bahasa Arab}

Bahasa Arab sudah menjadibahasa internasional, buktinya dengan ditetapkannya tanggal 18 desember adalah hari bahasa Arab internasional. Bahkan sudah digunakan dalam bahasa sehari-hari dan juga sebagai pola pergaulan anak-anak muda pada zaman sekarang, dengan itu sudah dapat di akui sebagai bahasa internasional dan juga di sekolah -sekolah di dunia misalnya Amerika,Afrika,Singapura, India dan negara lainnya yang menuntut para pelajar untuk mengetahui Bahasa Arab. Bahka saat ini bahasa Arab sudah mulai digunakan oleh beberapa Organisasi yang ada di dunia.

Maka dari itu, guru bahasa Arab tidak hanya dituntut menguasai kemampuan atau kemahiran berbahasa tetapi juga harus mempunyai kemampuan pedagogis. Hal itu bertujuan agar pembelajaran bahasa dapat diterima oleh siswa dengan pendekatan, metode, teknik, yang berbeda sesuai dengan kondisi pembelajaran. Stevick (1982) berpendapat bahwa tugas guru bahasa meliputi tiga hal, yaitu mengembangkan kompetensi komunikasi, mengembangkan kompetensi linguistik, mengembangkan kompetensi personal ${ }^{18}$

Dalam pembahasan selanjutnya, akan penulis paparkan tentang kontribusi linguistik pedagogis terhadap pembenahan mutu pembelajaran bahasa Arab.

\section{Metode Penelitian}

Metode yang digunakan dalam tulisan ini yaitu studi pustaka, yaitu dengan mengumpulkan berbagai literatur tentang linguistik pedagogis dan literatur tentang mutu pembelajaran bahasa Arab, yang kemudian disintesiskan penulis sehingga menjadi salah satu solusi pembenahan mutu pembelajaran bahasa Arab di sekolah agar menjadi lebih baik lagi

18 Bambang Widiatmoko, "Pemanfaatan Hasil Penelitian Linguistik Pedagogis dalam Peningkatan Kualitas Pembelajaran di Sekolah,” Turats Vol 4 No 1 (Juni 2008): 7. 


\section{Pembahasan}

Linguistik pedagogis merupakan cabang dari linguistik terapan. Berikut penjelasannya:

\section{Pengertian linguistik pedagogis}

Linguistik edukasional atau linguistik pedagogis merupakan salah satu cabang ilmu linguistik terapan yang khusus menganalisis, menerangkan, dan menjelaskan tentang praktik pelaksanaan pengajaran bahasa dan pendidikan bahasa yang berlandaskan teori-teori kebahasaan ${ }^{19}$

Menurut (Hornberger, 2001; Spolsky, 1978) menyatakan bahwa "Educational linguistics is an area of study that integrates the research tools of linguistics and other related disciplines of the social sciences in order to investigate holistically the broad range of issues related to language and education", yang mengandung arti bahwa linguistik pedagogis atau linguistic edukasional adalah bidang studi yang mengintegrasikan alat penelitian linguistik dan disiplin lainnya yang berkaitan dengan ilmu-ilmu sosial dalam rangka menyelidiki secara menyeluruh pada berbagai masalah yang berkaitan dengan bahasa dan pendidikan ${ }^{20}$

Jika Psikolinguistik mengajarkan teori-teori belajar bahasa. Sosiolinguistik mengajarkan bagaimana penggunaan bahasa itu secara aktual dalam komunikasi, maka linguistik pedagogis menyangkut seluruh aspek baik dari psikolinguistik maupun sosiolinguistik dalam satu peran dalam pembelajaran bahasa

Lingustik pedagogis dalam pembelajaran bahasa muncul bersama dengan dua pertanyaan yang tidak dipisahkan satu sama lain, yaitu "apakah yang dipelajari dari bahasa?" dan "bagaimana cara mengajar bahasa?"soal pertama mendedikasikan tentang konten bahasa, dan soal kedua mendedikasikan tentang cara/metode. Maka jawaban dari soal pertama ada dalam ilmu linguistik, sosiolinguistik, psikolinguistik. Dan jawaban dari soal kedua ada pada linguistik pedagogis, dan psikolinguistik ${ }^{21}$.

Dengan ilmu pengetahuan yang menjadi dasar itu, ditentukan prinsip prinsip belajar mengajar bahasa, dipilihlah metode yang cocok cocok untuk pengajaran bahasa: pendekatan, metode, teknik, silabus, dan hasil yang ingin dicapai. Jika semua itu telah disepakati, maka tugas yang terakhir ialah guru bahasa di kelas ${ }^{22}$.

Menurut H.H Stern. Sa berpendapat bahwa dalam linguistik edukasional orang bergelut dengan empat konsep utama, yaitu: Bahasa, Pengajaran, Pelajaran, dan Konteks. Dengan mengajukan beberapa pertanyaan sederhana tentang empat konsep

19x Parera, 1.

20x Bernard Spolsky, Educational Linguistics: An Introduction terj. Rowley (London: Newbury House, 1978), 65.

.عبده راجحي, علم اللغة التطبيقي و تعليم اللغة (دار الفرقة الجامعية الجامعة الإسكندرية, 1995), 2721 . 21 .

22 Parera, Linguistik Edukasional, 2. 
tersebut, orang dapat merumuskan, meramalkan, mengartikan, dan mengevaluasi teori teori pembelajaran bahasa ${ }^{23}$.

1. Pengajaran bahasa memerlukan konsep tentang hakikat bahasa. Secara implisit dan eksplisit seorang guru bahasa bekerja berlandaskan teori teori tentang bahasa. Oleh karena itu, satu pertanyaan sentral yang diajukan tentang teori pengajaran bahasa ialah: apa pandangan tentang bahasa dalam teori pengajaran bahasa itu? Bidang ilmu yang dapat memberikan jawaban pertanyaan itu adalah linguistik, psikolinguistik, sosiolinguistik, dan studi khusus tentang bahasa bahasa tertentu(linguistik deskriptif)

2. Pengajaran bahasa menuntuk pandangan tentang pelajar bahasa dan hakekat pelajaran bahasa. Pertanyaan yang menjadi dasar ialah: pelajar bahasa yang seperti apa yang disebutkan teori tertentu dan bagaimana ia melihat bahasa?. Bidang ilmu yang berkembang dengan pertanyaan ini adalah psikologi, psikologi pendidikan, dan psikolinguistik untuk pelajaran bahasa dan penggunaan bahasa.

3. Pengjaran bahasa melibatkan guru bahasa dan pengajaran bahasa. Pertanyaan yang diajukan adalah bagaimana teori teori itu mengartikan pengajaran bahasa?, apa peranan dan tugas yang dibebankan pada guru? Bagaimana pengajaran bahasa dideskripsikan dan dianalisis? Bidang ilmu yang berhubungan langsung dengan pertanyaan ini adalah studi pendidikan.

4. Pengajaran bahasa berlangsung dalam satu konteks tertentu. Pengertian tentang konteks ialah bagian yang esensial dari teori. Bahasa, belajar bahasa, dan mengajar bahasa harus dilihat dalam satu konteks, tempat/ penempatan, dan latar belakang. Berhubungan dengan itu lahirlah tiga perangkat pertanyaan.

Berdasarkan ilmu pengetahuan yang menjadi dasar itu, dapat ditentukan prinsipprinsip belajar mengajar bahasa, dipilih metodologi yang cocok untuk pengajaran bahasa: pendekatan, metode, teknik, silabus, dan hasil yang ingin dicapai. Jika semua itu telah disepakati, maka tugas yang terakhir ialah guru bahasa di kelas. Proses belajar mengajar bahasa bermula dengan satu keputusan dan kebijaksanaan sesuai dengan kehendak politik dan masyarakat. Kebijaksanaan itu memerlukan pengorganisasian dan pengadministrasian sebagai sarana. Tentu saja dibutuhkan ilmu-ilmu pendukung yang relevan: pendidikan, linguistik, psikologi, teori-teori masyarakat, psikolinguistik, dan sosiolinguistik.

Pembelajaran bahasa Arab sangat membutuhkan kontribusi dari beberapa disiplin ilmu dalam membenahi pembelajaran bahasa Arab agar lebih baik lagi. Linguistik pedagogis salah satunya, karena dalam pengertian linguistik pedagogis pun menjelaskan tentang praktik pelaksanaan pengajaran bahasa dan pendidikan bahasa yang berlandaskan teori-teori kebahasaan. Guru bahasa Arab yang menjadi tugas akhir linguistik pedagogis harus mengetahui tugasnya, dan apa saja yang

23 Bernard Spolsky, Educational Linguistics: An Introduction terj. Rowley (London: Newbury House, 1978), 65. 
harus dipersiapkan untuk menjadi guru yang baik agar dapat memperbaiki mutu pembelajaran bahasa Arab, sehingga sebuah kewajiban bagi guru untuk mengetahui dan mempelajari linguistik pedagogis lebih dalam lagi agar tercipta pembelajaran yang lebih efektif sehingga dapat meningkatkan mutu pembelajaran bahasa Arab yang lebih baik lagi.

Berdasarkan catatan, penulis sintesiskan bahwasanya linguistik pedagogis dalam pembelajaran bahasa Arab adalah merupakan salah satu cabang ilmu linguistik terapan yang khusus menganalisis, menerangkan, dan menjelaskan tentang praktik pelaksanaan pengajaran bahasa dan pendidikan bahasa Arab yang berlandaskan teoriteori kebahasaan. Sebagaimana menyusun metode, teknik, dan silabus pembelajaran bahasa Arab.

\section{Pembenahan mutu pembelajaran bahasa Arab}

Mutu pembelajaran diidentifikasi sebagai tingkat keunggulan suatu proses pembelajaran, tingkat kesesuaian rancangan pembelajaran dengan fungsi dan penggunaannya. ${ }^{24}$ Sementara itu, Ahmad Rifandi mendefinisikan mutu pembelajaran sebagai capaian pembelajaran yang dipengaruhi oleh multifaktor seperti, profesionalitas pengajar, fasilitas pembelajaran, media pembelajaran, budaya institusi, siswa/mahasiswa, metode pembelajaran, dan jenis program. ${ }^{25}$ Berbeda dengan Abdul Wahab Rosyidi yang menjelaskan bahwa kata "mutu" tidak memiliki derajat kebakuan mengenai apa sesungguhnya arti kata mutu tersebut. Hal ini disebabkan perbedaan latar belakang seseoarang dan sudut pandang profesi yang sangat menentukan untuk mengatakan apakah sesuatu dapat dikatakan bermutu atau tidak.

Dalam hal ini Rosyidi hanya menjelaskan bahwa mutu merujuk pada derajat keunggulan suatu produk atau hasil kerja, baik berupa barang maupun jasa. Akan halnya dalam dunia pendidikan, mutu tidak dapat dilihat, akan tetapi dapat dirasakan. ${ }^{26}$ Meskipun demikian, Imam Makruf menekankan mutu pembelajaran terletak pada proses pembelajaran. Proses pembelajaran yang bermutu menurutnya akan mengantarkan setiap siswa pada pencapaian hasil yang maksimal. Kata mutu pembelajaran menurut Makruf mengandung dua makna sekaligus yaitu, sebuah filosofi sekaligus sebagai metodologi mengenai ukuran dan tingkat baik buruk suatu benda yang digunakan suatu lembaga sebagai rancangan perubahan, mengatur rancangan agenda, serta menghadapi berbagai tekanan. Sebagai filosofi mutu pembelajaran memandang pembelajaran bukan sebatas kegiatan transfer pengetauan (ranah intelektual), tetapi juga mengembangkan karakter, moral, nilai-nilai, dan budaya peserta didik. Sementara sebagai metodologi, mutu pembelajaran bermakna

24 Imam Makruf,"Standarisasi Mutu Pembelajaran: Studi di IAIN Surakarta dan Kasem Bundit University Thailand", Jurnal Shahih, Vol. 1, No. 1, Th . 2016, hlm. 101.

25 Ahmad Rifandi," Mutu Pembelajaran dan Kompetensi Lulusan Diploma III POLITEKNIK", Jurnal Cakrawala Pendidikan, Feb 2013, XXXII, No. 1., hlm. 126.

26 Abdul Wahab Rosyidi,"Manajemen Mutu Pembelajaran Bahasa Arab di Madrasah Sebagai Pilar Pengembangan Perguruan Tinggi Islam DI Indonesia", hlm. 3-4. 
sebuah sistem rancangan untuk mencapai hasil yang telah ditentukan dalam pembelajaran. ${ }^{27}$ Secara lebih luas Edi Suhadi (dkk) menjelaskan mutu pembelajaran sebagai keberhasilan sekolah dalam mencapai tujuan pembelajaran.

Dalam pelaksanannya, mutu pembelajaran merupakan perpaduan antara proses dan hasil belajar yang dicapai pembelajar dengan dukungan pendidik dan tenaga kependidikan. Pembelajaran bermutu bila semua unsur berpadu menunjukkan kinerja terbaiknya dalam melaksanakan tugas dan tanggungjawabnya. ${ }^{28}$

Dengan demikian mutu pembelajaran adalah seperangkat asumsi filosofis mengenai proses pembelajaran yang dapat mengantarkan pembelajar pada pencapaian tujuan belajar yang telah ditetapkan secara maksimal, bahwa pembelajaran yang bermutu tidak hanya berupa transfer pengetahuan (aspek intelektual), lebih dari itu pembelajaran yang bermutu adalah pembelajaran yang juga berhasil mengantarkan pembelajar yang terampil (aspek psikomotor) disertai moral (aspek afeksi) yang baik. Mutu pembelajaran juga merupakan sebuah metodologi yang berisi seperangkat rancangan perubahan, rancangan agenda dan rancangan problem solving dari sebuah sistem pembelajaran yang terpadu antara pembelajar, pendidik dan tenaga kependidikan untuk mencapai tujuan pembelajaran yang telah ditetapkan. Dengan demikian mutu pembelajaran adalah cerminan dari sekolah/madrasah yang berhasil dalam melaksanakan proses belajar-mengajar.

Setiap proses pembelajaran dilaksanakan guna mencapai tujuan yang telah ditetapkan ${ }^{29}$. Oleh sebab itu, semakin tinggi peluang tercapainya tujuan dalam pembelajaran tercipta, semakin tinggi pula mutu pembelajaran tersebut. Berpangkal pada pemahaman mutu pembelajaran di atas, pembelajaran yang bermutu ${ }^{30}$ bermuara pada sebuah proses yang terfokus pada pembelajar, dibingkai dengan aktifitas yang menyenangkan, bergembira, dan demokratis dalam menghargai setiap pendapat, sehingga pada akhirnya substansi setiap pembelajaran benar-benar dihayati. ${ }^{31}$

Dari beberapa pengertian diatas, penulis sintesiskan bahwasanya yang dimaksud dengan pembenahan mutu pembelajaran bahasa Arab adalah perbaikan seperangkat asumsi filosofis mengenai proses pembelajaran yang dapat mengantarkan pembelajar pada pencapaian tujuan belajar yang telah ditetapkan secara maksimal yang juga merupakan sebuah metodologi yang berisi seperangkat rancangan perubahan, rancangan agenda dan rancangan problem solving dari sebuah sistem pembelajaran

27 Imam Makruf,"Standarisasi Mutu Pembelajaran: Studi di IAIN Surakarta dan Kasem Bandit University Thailand", Jurnal Shahih, Vol.1, Januari-Juni, 2016, hlm. 102.

28 Edi Suhadi (dkk),"Pengebangan Motivasi dan Kompetensi Guru dalam Peningkatan Mutu Pembelajaran Madrasah", Jurnal Ta'dibuna, Vol. 3, No. 1, April 2014, hlm. 48.

29 Wina Sanjaya, Perencanaan dan Desain Pembelajaran, (Jakarta: Kencana, 2013), hlm. 10. Dalam Larin W. Anderson dan David R. Krathwohl, Pembelajaran, Pengajaran dan Asesmen, (Yogyakarta: Pustaka Pelajar, 2010), hlm. 18.

30 Pasi Sahlberg, Finnish Lessons, (Bandung: PT Mizan Pustaka, 2014), hlm. 133.

31 Imam Makruf,"Standarisasi Mutu Pembelajaran: Studi di IAIN Surakarta dan Kasem Bundit University Thailand", hlm. 103. 
yang terpadu antara pembelajar, pendidik dan tenaga kependidikan untuk mencapai tujuan pembelajaran yang telah ditetapkan. Yang menjadi fokus penulis disini adalah guru, sebagai tugas akhir dari linguistik pedagogis.

Pembelajaran yang bermutu dihasilkan oleh guru yang bermutu pula. Kecakapan guru dalam mengelola proses pembelajaran menjadi inti persoalannya. Begitu pula jika seorang guru bahasa Arab mempunyai mutu yang bagus, maka akan menghasilkan pembelajaran bahasa Arab yang bagus pula. Tahapan-tahapan dalam proses pembelajaran sedikitnya harus meliputi fase-fase berikut (Surakhmad 1986:45$46)^{32}$ :

1. Menetapkan tujuan pembelajaran yang kan dicapai

2. Memilih dan melaksanakan metode yang tepat dan sesuai materi pelajaran serta memperhitungkan kewajaran metode tersebut dengan metode-metode yang lain

3. Memilih dan mempergunakan alat bantu atau media guna membantu tercapainya tujuan

4. Melakukan penilaian atau evaluasi pembelajaran

Menurut penjelasan diatas, penulis sintesiskan bahwasanya mutu pembelajaran bahasa Arab dapat dibenahi melalui metodologi pembelajarannya, yang akan disalurkan langsung oleh guru bahasa Arab sebagai tugas akhir linguistik pedagogis.

\section{Kontribusi linguistik pedagogis pada pembenahan mutu pembelajaran bahasa Arab}

Pembelajaran bahasa Arab tidak dapat berlangsung dengan baik tanpa memanfaatkan jasa ilmu ilmu lain yang relevan dengannya. Termasuk didalam linguistik pedagogis yang di payungi oleh linguistik terapan. Di dalam linguistik pedagogis ahli bahasa juga berperan menjelaskan fenomena bahasa yang bersifat alamiah, menganalisis bahasa permasalahan bahasa,dsb. Sedangkan tugas akhir dari linguistik pedagogis adalah guru bahasa. Tugas utama guru bahasa adalah berusaha agar anak didik menjadi tuntas dalam belajar bahasa. Tugas guru mengajarkan bahasa, bukan mengajarkan teori bahasa, akan tetapi mengajarkan anak didik terampil dalam menggunakan bahasa. Menurut Bell (1987) terdapat tiga perbedaan antara ahli bahasa dengan guru bahasa ${ }^{33}$.

1. tugas guru bahasa adalah membimbing anak didik agar tuntas dalam belajar bahasa; sedangkan tugas ahli bahasa adalah menjelaskan fenomena bahasa yang bersifat alamiah

2. Aspek metode: guru bahasa menggunakan metode fungsional dan praktis; sedangkan ahli bahasa menggunakan metode abstrak dan formal.

32 Surakhmad, W. 1986. Metodologi Pengajaran Nasional. Bandung: Jemmars

33 Parera, Linguistik Edukasional, 12. 
3. Aspek sikap: guru bahasa bersikap bahwa bahasa adalah seperangkat keterampilan; sedangkan ahli bahasa bersikap bahwa bahasa yang dihadapi memiliki sistem, baik dalam bentuk maupun makna.

Guru bahasa Arab tidak hanya dituntut menguasai kemampuan atau kemahiran berbahasa tetapi juga harus mempunyai kemampuan pedagogis. Hal itu bertujuan agar pembelajaran bahasa dapat diterima oleh siswa dengan pendekatan, metode, teknik, yang berbeda sesuai dengan kondisi pembelajaran. Stevick (1982) berpendapat bahwa tugas guru bahasa meliputi tiga hal, yaitu mengembangkan kompetensi komunikasi, mengembangkan kompetensi linguistik, mengembangkan kompetensi personal $^{34}$

Seorang guru bahasa Arab seharusnya menguasai linguistik apabila dia ingin menjadi guru yang baik. Guru bahasa Arab harus menguasai fonologi, morfologi, sintaksis, semantik, dan ilmu-ilmu sekerabat denganlinguistik, misalnya sosiolinguistik dan psikolinguistik. Jika dalam pembelajaran bahasa Arab, tentu saja guru bahasa Arab harus menguasai kaidah bahasa, nahwu, shorof, ilmu dilalah, juga tentu saja pengetahuan linguistik bagi seorang guru bahasa Arab lebih bersifat praktis dalam arti membentengi dirinya agar dapat menjelaskan gejala bahasa yang diajarkannya ${ }^{35}$

Guru bahasa Arab tidak boleh hanya mengajarkan kaidah bahasa Arab saja. Kaidah bahasa dapat diajarkan untuk menuntun pola penggunaan bahasa ketika anak didik berkomunikasi. Guru sebaiknya memahami bagaimana agar kaidah bahasa yang dianalisis berdasarkan konsep linguistik dapat menampakkan diri di dalam pemakaian bahasa anak didik. Hal itu perlu ditekankan karena guru bahasa tidak mengajarkan anak didik menjadi ahli bahasa, tetapi berusaha agar anak didik mahir berbahasa $^{36}$.

Zaman sudah berkembang, begitupula bahasa. Seorang guru harus mampu meng update pengetahuan berbahasanya sesuai dengan zaman, karena sifat bahasa itu sendiri adalah berkembang ${ }^{37}$. Dalam beberapa permasalahan pembelajaran bahasa, salah satu yang menjadi problem adalah minat siswa terhadap pembelajaran tersebut. Siswa sebagai pemeran utama pembelajaran adalah subjek belajar yang menuntut guru untuk mengembangkan pengetahuannya. Alih-alih menguasai bahasa Arab, kebanyakan siswa kurang apresiatif terhadap pembelajaran bahasa Arab, personalia guru bahasa Arab, metode pengajaran yang diterapkan, tingkat kebosanan dalam proses pembelajaran yang masih tinggi ${ }^{38}$. Hal ini semakin menegukan potret

34 Bambang Widiatmoko, "Pemanfaatan Hasil Penelitian Linguistik Pedagogis dalam Peningkatan Kualitas Pembelajaran di Sekolah,” Turats Vol 4 No 1 (Juni 2008): 7.

35 Abdul Hamid, Pembelajaran Bahasa Arab (Malang: UIN MALIKI PRESS, 2008), 34.

36 Parera, Linguistik Edukasional, 9.

37 Abdul Muhbib, Pemikiran Linguistik Tammam Hassan dalam Pembelajaran Bahasa Arab (Jakarta: UIN Jakarta Press, 2009), 13.

38 Hairul Rahman, "Upaya Guru dalam Menumbuhkan Motivasi Belajar Bahasa Arab,Skripsi," Repository FITK UIN Sunan Kalijaga, 2008, 23. 
rendahnya mutu pembelajaran bahasa Arab di Indonesia ${ }^{39}$. Dalam membenahi mutu pembelajaran bahasa Arab salah satunya adalah dengan merancang metodologi atau silabus pembelajaran bahasa Arab dengan baik. Disini kita akan melihat kontribusi linguistik pedagogis terhadap pembenahan mutu pembelajaran bahasa Arab agar lebih baik lagi sesuai dengan operasi pembelajaran menurut Parera (Parera:1989) ${ }^{40}$

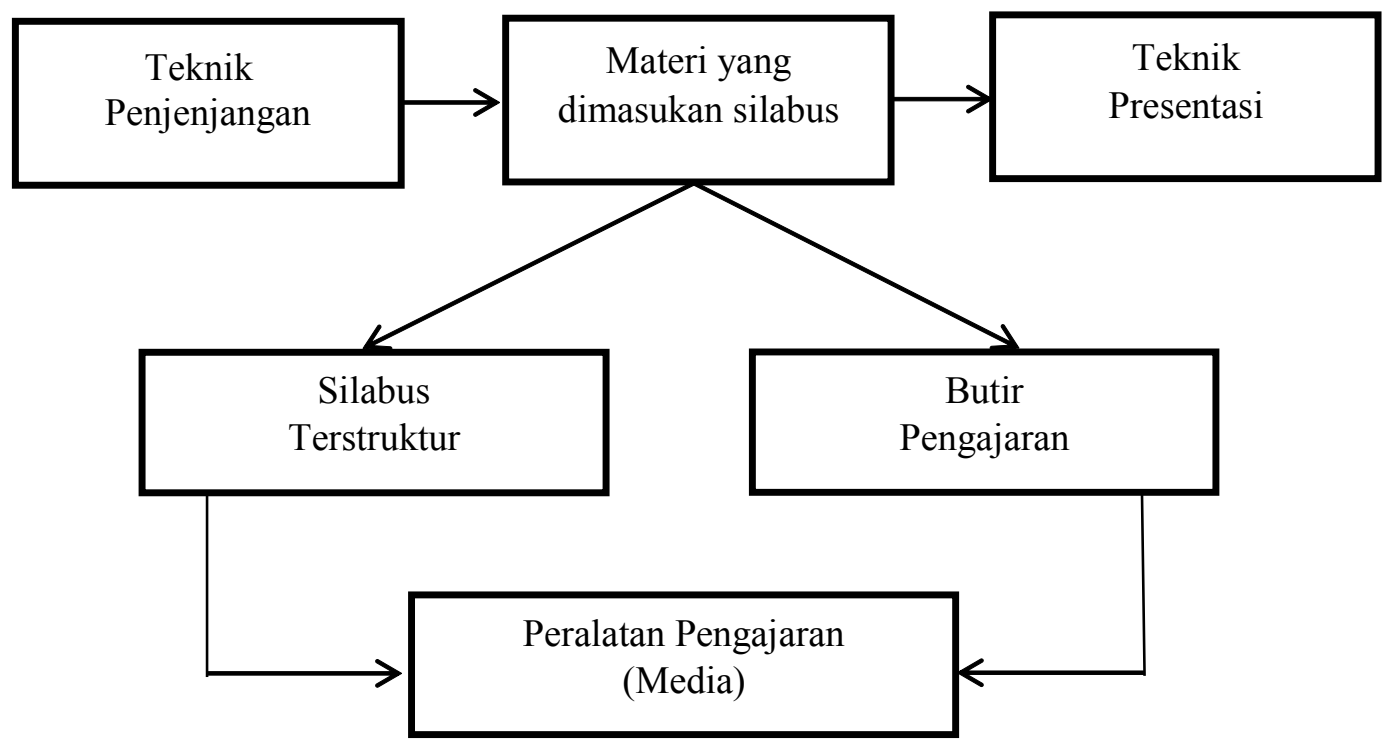

Dari konsep di atas, dapat dijelaskan bahwa sebuah teknik penjenjangan(taqniyah mustawa) merupakan langkah awal dalam sebuah pembelajaran untuk menentukan langkah selanjutnya, apakah siswa merupakan jenjang pembelajar pemula atau tengah. Sehingga dalam menyusun materi (Al Maddah) yang akan dimasukkan ke dalam silabus sudah sesuai dengan jenjang masing masing siswa. Setelah menyusun materi Al Maddah), ada sebuah teknik presentasi atau metode (At Thariqah) yang juga sangant penting dalam sebuah proses pembelajaran, paham atau tidaknya siswa akan sebuah materi, dibutuhkan sebuah teknik yang ampuh yang harus dimiliki guru. Dari beberapa hal tersebut, maka jadilah silabus terstruktur (Takhtith at Tadris) dan sebuah butir pengajaran (Bundiyatu Ta'lim), yang kemudian akan di aplikasikan dengan menggunakan sebuah alat pembelajaran atau lebih kita kenal dengan sebutan media pembelajaran (Wasail at Tadris).

Dari beberapa catatan, penulis sintesiskan bahwa untuk memperbaiki mutu pembelajaran bahasa Arab, maka hal pertama yang diperbaiki adalah silabus operasi pembelajaran agar tercipta pembelajaran yang menyenangan dan efektif, jika sebuah proses pembelajaran sesuai dengan silabus operasi pembelajaran yang dibalut dengan suasana belajar yang menyenangkan, maka akan berpengaruh nyata pada siswa dalam menyerap ilmu bahasa Arab yang disampaikan, sehingga proses pembelajaran bahasa Arab menjadi efektif. Dengan begitu, maka sangat memungkinkan bagi sebuah sekolah untuk meningkatkan mutu pembelajaran bahasa Arab dengan lebih baik lagi.

39 Buhori, "Peran Psikolinguitik dalam Pembelajaran Bahasa Arab” Vol 5 No 1 (Maret 2017): 5.

40 Parera, Linguistik Edukasional, hal 35 


\section{E. Penutup}

Dalam pembelajaran bahasa Arab, dibutuhkan disiplin disiplin ilmu lainnya yang relevan, seperti halnya linguistik pedagogis. Linguistik pedagogis dalam pembelajaran bahasa Arab adalah merupakan salah satu cabang ilmu linguistik terapan yang khusus menganalisis, menerangkan, dan menjelaskan tentang praktik pelaksanaan pengajaran bahasa dan pendidikan bahasa Arab yang berlandaskan teoriteori kebahasaan. Sebagaimana menyusun metode, teknik, dan silabus pembelajaran bahasa Arab.

Pembelajaran bahasa Arab membutuhkan kontribusi dari ilmu disiplin lain yang relevan untuk membenahi mutu pembelajaran bahasa Arab agar lebih baik lagi. Pembenahan mutu pembelajaran bahasa Arab adalah perbaikan seperangkat asumsi filosofis mengenai proses pembelajaran yang dapat mengantarkan pembelajar pada pencapaian tujuan belajar yang telah ditetapkan secara maksimal yang juga merupakan sebuah metodologi yang berisi seperangkat rancangan perubahan, rancangan agenda dan rancangan problem solving dari sebuah sistem pembelajaran yang terpadu antara pembelajar, pendidik dan tenaga kependidikan untuk mencapai tujuan pembelajaran yang telah ditetapkan. Yang menjadi fokus penulis disini adalah guru, sebagai tugas akhir dari linguistik pedagogis.

Untuk memperbaiki mutu pembelajaran bahasa Arab, linguisti pedagogis memberikan kontribusi, salah satunya adalah dengan memberikan beberapa silabus operasi pembelajaran bahasa Arab. Maka dari itu,hal pertama yang diperbaiki adalah silabus operasi pembelajaran agar tercipta pembelajaran yang menyenangan dan efektif, jika sebuah proses pembelajaran sesuai dengan silabus operasi pembelajaran yang dibalut dengan suasana belajar yang menyenangkan, maka akan berpengaruh nyata pada siswa dalam menyerap ilmu bahasa Arab yang disampaikan, sehingga proses pembelajaran bahasa Arab menjadi efektif. Dengan begitu, maka sangat memungkinkan bagi sebuah sekolah untuk meningkatkan mutu pembelajaran bahasa Arab dengan lebih baik lagi.

\section{Daftar Pustaka}

Buhori. "Peran Psikolinguitik dalam Pembelajaran Bahasa Arab" Vol 5 No 1 (Maret 2017).

Benson, Carol. 2005. The importance of mother tongue-based schooling for educational quality. Stockholm: Stockholm University Press.

Christie,Frances., Unsworth,Len. 2015. Developingdimensionsof aneducationallinguistics. web.uam.es / departamentos / filoyletras / .../LFC... / ChristieUnsworth05.doc

Hamid, Abdul. Pembelajaran Bahasa Arab. Malang: UIN MALIKI PRESS, 2008.

Ismail, Mochamad. "PERANAN PSIKOLINGUISTIK DALAM PEMBELAJARAN BAHASA $A R A B$ ” Vol 8 No 2 (2013). https: / / ejournal.unida.gontor.ac.id/index.php/tadib/ article/view/508. 
Muhajir. Arah Baru Pengajaran Bahasa Arab. Yogyakarta: FITK UIN SUKA, 2017.

Muhbib, Abdul. Pemikiran Linguistik Tammam Hassan dalam Pembelajaran Bahasa Arab. Jakarta: UIN Jakarta Press, 2009.

Nababan. Metodologi Pengajaran Bahasa. Jakarta: Gramedia Pustaka Utama, 1993.

Parera, Daniel. Linguistik Edukasional. Jakarta: Erlangga, 1987.

Rahman, Hairul. "Upaya Guru dalam Menumbuhkan Motivasi Belajar Bahasa Arab,Skripsi.” Repository FITK UIN Sunan Kalijaga, 2008.

Richards, Jack C. and Richard Schmidt. 2002. Dictionary of Language Teaching and Applied Linguistics. London: Longman

Surakhmad, W. Metodologi Pengajaran Nasional. Bandung: Jemmars, 1986.

Spolsky, Bernard. Educational Linguistics: An Introduction terj. Rowley. London: Newbury House, 1978.

Widiatmoko, Bambang. "Pemanfaatan Hasil Penelitian Linguistik Pedagogis dalam Peningkatan Kualitas Pembelajaran di Sekolah.” Turats Vol 4 No 1 (Juni 2008).

Zamroni, Meningkatkan Mutu Sekolah, (Jakarta : PSAP Muhamadiyah, 2007)

عبده رمجي. علم اللغة التطبيقي و تعليم اللغة. دار الفرقة الجامعية الجامعة الإسكندرية, 1995. 